given intravenously. Continued administration may lead to hyponatraemia and hypokalaemia through excessive loss of sodium and potassium.

We report these cases for two reasons; firstly, to re-emphasise the fact that the skin is not a completely impermeable barrier and, secondly, as a reminder that although urea itself is not a particularly toxic substance, other drugs that are used in the treatment of ichthyotic skin conditionsfor example, salicylates and retinoids-are potentially more toxic, especially when absorbed systemically.

We thank Dr D Haigh and Dr P Dear for permission to report their patients.

\section{References}

' Harpin VA. Rutter N. Barrier properties of the newborn infants skin. J Pediatr 1983;102:419-25.
2 Curley A, Hawk RE, Kimbrough RD, Nathenson G, Finberg L. Dermal absorption of hexachlorophane in infants. Lancet 1971;ii:296-7.

${ }^{3}$ Harpin VA. Rutter N. Percutancous alcohol absorption and skin necrosis in premature infants. Arch Dis Child 1982;57:477-9.

${ }^{4}$ Fcinblatt BI. Aceto T, Bechom G, Bruck E. Percutancous absorption of hydrocortisone in children. Am J Dis Child 1966;112:218-23.

5 Chabrolle JP, Rossier A. Goitre and hypothyroidism in the newborn infant after cutancous absorption of iodine. Arch Dis Child 1978;53:495-8.

6 Evans NJ, Rutter N, Hadgraft J, Parr G. Percutaneous admiristration of theophylline in the preterm infant. $J$ Pediatr 1985;107:307-11.

Correspondence to Dr D W Beverley, St James's University Hospital, Leeds, West Yorkshire, England.

Received 17 February 1986

\title{
Inadequate humidification of respiratory gases during mechanical ventilation of the newborn
}

\author{
W O TARNOW-MORDI, P SUTTON, AND A R WILKINSON \\ Neonatal Unit, Department of Paediatrics, John Radcliffe Hospital, Oxford
}

SUMMARY Proximal airway humidity was measured during mechanical ventilation in 14 infants using an electronic hygrometer. Values below recommended minimum humidity of adult inspired gas were recorded on 251 of 396 occasions. Inadequate humidification, largely due to inadequate proximal airway temperature, is commoner than recognised in infants receiving mechanical ventilation.

Little is known about actual values of inspired gas humidity during mechanical ventilation of infants. The British Standard recommends as adequate a minimum of $33 \mathrm{mg} \mathrm{H} \mathrm{H}_{2} \mathrm{O} / \mathrm{l}$ of inspired gas in adults and older children receiving ventilatory help.' Previously described methods for measuring gas humidity have included the use of chemical absorptive agents, estimation of dew point, wet and dry bulb thermometry, gravimetry, ${ }^{2}$ and mass spectrometry. ${ }^{3}$ None has proved easy to use in clinical practice. Electronic hygrometry is a recent technique that seems more suitable for clinical use. ${ }^{4}$ We describe the first experience with a small, commercially available, electronic hygrometer in monitoring gas humidity in the proximal airway of mechanically ventilated infants.

\section{Methods}

The device is a battery operated hygrometer (Rotronics Hygroskop GTL, Centronics Sales Ltd, Croydon) measuring $25 \times 6 \mathrm{~cm}$. Temperature is determined by a heat sensitive thermocouple and relative humidity by a capacitive sensor. This is an organic polymer dielectric whose capacitance varies linearly with ambient moisture content between $0-100 \%$ relative humidity. Its response is non-linear in supersaturated atmospheres, tending to overestimate relative humidity above $100 \% .^{4}$

The sensor and thermocouple were most conveniently placed in the patient manifold of the ventilator circuit 3-6 cm distal to the temperature probe of the humidifier. At this site the device estimated the average humidity of inspired and expired gas, not that of inspired gas alone. Absolute humidity was calculated from relative humidity using values of saturated water vapour pressure in standard tables. ${ }^{5}$ No attempt was made to correct for daily variations in atmospheric pressure, the rise in pressure in the circuit due to positive pressure ventilation, or the variation in estimation of relative humidity between air and $100 \%$ oxygen.

Humidity measurements. The humidity sensor was 
calibrated in an airtight chamber at $30^{\circ} \mathrm{C}-40^{\circ} \mathrm{C}$ for one to four hours over saturated solutions of seven crystalline salts. A mean of three to six readings of relative humidity was taken. The predicted value of relative humidity was taken from standard tables. ${ }^{5}$ Measurements of proximal airway temperature and humidity were made in infants receiving artificial ventilatory help using Fisher Paykel MR 310 and MR 320 and Bennett Cascade II humidifier systems. Clinical staff were responsible for the ventilator and humidifier settings. The infants were between 2 hours and 3 months old. Measurements were discontinuous and made during periods lasting between one and 36 hours. The infants were nursed under a radiant heat source, and the humidifier temperature probes in the ventilator inspiratory tubing were not shielded.

\section{Results}

Over saturated salts, the hygrometer estimated relative humidity to within $\pm 2 \%$ of predicted values over the range $0-100 \%$. Altogether, 396 measurements of proximal airway humidity and temperature were made in 14 infants. In $30(8 \%)$ measurements the hygrometer registered values of relative humidity above $100 \%$. This was attributed to condensation on the sensor after prolonged exposure to saturated gas rather than true supersaturation, which is rarely encountered with water heaters of the type used in this study. ${ }^{6}$ These measurements were recorded as $100 \%$ relative humidity. At constant temperature the correlation between proximal airway humidity and flow rate was inverse in infants managed with the Fisher Paykel systems

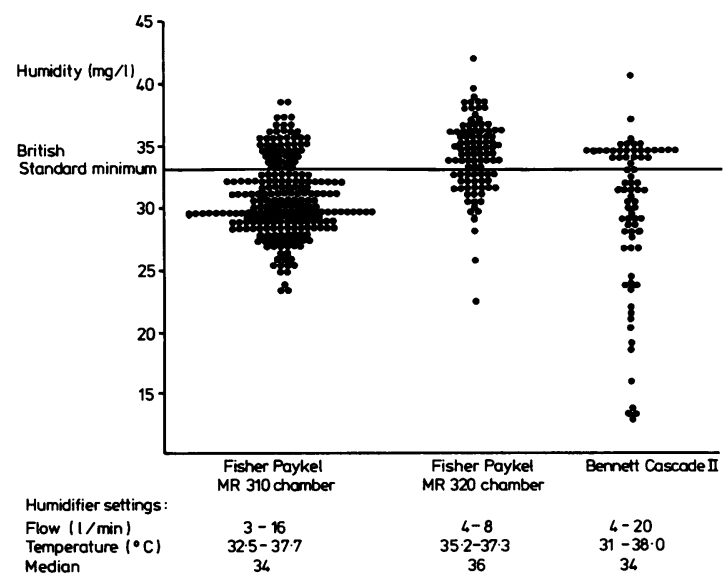

Figure Measurements of proximal airway gas humidity in 14 mechanically ventilated infants.
Table Relation between inadequate humidification ${ }^{1}$ in the proximal airway $\left(<33 \mathrm{mg} \mathrm{H}_{2} \mathrm{O} / \mathrm{l}\right)$ and presence of dry expiratory tubing in 364 measurements

\begin{tabular}{llc}
\hline $\begin{array}{l}\text { Proximal airway } \\
\text { humidity }\end{array}$ & \multicolumn{2}{l}{ Expiratory tubing $($ No $(\%))$} \\
\cline { 2 - 3 } & Wet & Dry \\
\hline$\geqslant 33 \mathrm{mg} \mathrm{H} \mathrm{H}_{2} \mathrm{O} / 1$ & $116(47)$ & $6(5)$ \\
$<33 \mathrm{mg} \mathrm{H} \mathrm{H}_{2} \mathrm{O} / 1$ & $131(53)$ & $111(95)$ \\
\hline Total & 247 & 117 \\
\hline
\end{tabular}

$\chi^{2}=58, d f=1, p<0 \cdot 0001$

$(\mathrm{r}=-0 \cdot 89, \mathrm{p}<\cdot 01)$ but direct with the Bennett Cascade II system $(r=0 \cdot 96, p<\cdot 001)$. Flow rates above $12 \mathrm{l} / \mathrm{min}$ were used on only 16 occasions.

Low values for proximal airway humidity [below the British Standard recommended minimum for inspired gas in adults of $\left.33 \mathrm{mg} \mathrm{H}_{2} \mathrm{O} / 1\right]^{6}$ were recorded on $251(63 \%)$ occasions (Figure) and were more frequent when the expiratory tubing was dry than when it was wet (Table). With all humidifiers there was a direct correlation between temperature, measured by the hygrometer, and absolute humidity in the proximal airway $(\mathrm{r}=0 \cdot 83, \mathrm{p}<\cdot 001)$. Only two measurements of proximal airway humidity throughout the study gave values above $40 \mathrm{mg}$ $\mathrm{H}_{2} \mathrm{O} / \mathrm{l}$.

\section{Discussion}

The electronic hygrometer is a simple and acceptable method of monitoring humidity in the proximal airway during intensive care. Its accuracy is comparable with that of mass spectrometry ${ }^{3}$ and of previous experience with electronic hygrometry. ${ }^{4}$

During spontaneous breathing gas inspired through mouth or nasopharynx reaches $37^{\circ} \mathrm{C}$ in the trachea. As it is fully saturated at this temperature it contains $44 \mathrm{mg} \mathrm{H}_{2} \mathrm{O} / 1$. During mechanical ventilation the endotracheal tube bypasses the nasopharyngeal mucosa, making the infant entirely dependent on an external source of humidity. In addition, as saturated expired gas mixes with inspiratory gas the values for proximal airway humidity reported here probably overestimate the true humidity of the infants' inspired gas. With the devices and settings used in this study, tracheal humidity is probably well below physiological levels. The Table indicates that wet expiratory tubing is no guarantee of adequate humidification, although dry expiratory tubing strongly suggests that humidification is inadequate.

The low range of proximal airway humidity documented here reflects the use of lower than physiological temperatures. In addition, the output 
from the humidifier water heaters may often have been suppressed owing to negative feedback from the temperature probes, which were not protected from the radiant heat source.

The Fisher Paykel systems produced lower humidity as gas flow increased, while the Bennett system achieved greater humidity at increasing flow rates. Electronic hygrometry may prove a useful method for comparative assessment of humidifiers.

Inadequate humidification of the respiratory tract may reduce mucociliary clearance and predispose to chronic lung disease in intubated infants. In conditions in which ciliary motility is deficient, such as cystic fibrosis or Kartagener's syndrome, there is chronic retention of secretions with radiographic appearances like those seen in the chronic lung disease of mechanically ventilated infants. Obstruction of small airways by secretions might also increase the risk of peripheral gas trapping and air leak.

As there are no data to define optimum humidity during ventilatory support of infants prospective randomised studies are needed to investigate (i) the relation between acute and chronic respiratory complications and ventilator circuit humidity and (ii) whether intermittent instillation of saline into the endotracheal tube reduces complications by increasing respiratory tract humidity.

We thank Professor M K Sykes of the Department of Anaesthetics and Dr M J Pilling of the Department of Physical Chemistry for their advice. WOT-M was supported by Action Research for the Crippled Child.

\section{References}

${ }^{1}$ British Standards Institution. Specifications for humidifiers for use with breathing machines. (BS 4494.) London: British Standards Institute, 1970.

2 Ingelstedt S. Studies on the conditioning of air in the respiratory tract. Acta Otolaryngol [Suppl] (Stockh) 1956;131:1-80.

${ }^{3}$ Hayes B, Robinson JS. An assessment of methods of humidification of inspired gas. Br J Anaesth 1970;42:94-104.

4 Nilsson GE. Measurement of water exchange through the skin. Med Biol Eng Comput 1977;15:209-18.

${ }^{5}$ Kaye GWC, Laby TH. Tables of physical and chemical constants. 14th ed. London: Longman, 1973.

${ }^{6}$ Klein EF, Shah DA, Shah NJ, et al. Performance characteristics of conventional and prototype humidifiers and nebulisers. Chest 1973;64:690-6.

Correspondence to Dr W Tarnow-Mordi, Department of Paediatrics, John Radcliffe Hospital, Headington, Oxford OX3 9DU, England.

Received 10 March 1986

\title{
Intellect after malignancy
}

\author{
V TWADDLE, P G BRITTON, J KERNAHAN, AND A W CRAFT \\ Departments of Psychiatry and Child Health, Royal Victoria Infirmary, Newcastle upon Tyne
}

SUMmary A previous study has shown that significant intellectual deficits exist in children treated for leukaemia but not in those with solid tumours. Unexpectedly, the deficits had not increased in the two years since the original study, suggesting that the nadir had already been reached five years after diagnosis.

The improving survival rates for children with cancer have led to a greater awareness of the side effects of treatment and their long term consequences. A study of intellectual function after treatment for leukaemia or solid tumours using sibling controls showed deficits in both groups, ${ }^{1}$ but these were consistently larger in the group with leukaemia. There was a suggestion that the deficits in children after treatment for leukaemia might be progressive, whereas for the other group they might be improving. This report details a further investigation of the same group of children two years after the initial assessment.

\section{Method}

Nineteen of the original group of 23 children with leukaemia (12 boys and seven girls) and 12 of the original group of 19 with solid tumours (eight boys and four girls) agreed to be retested with their siblings. Further details of the two groups are given in Table 1. Eleven of the patients with leukaemia and six of the patients with solid tumours were younger than their sibling.

Each child received the necessary four British ability scales according to their age. ${ }^{2}$ Thus all received the matrices test (abstract reasoning), the similarities test (verbal reasoning), and the recall of digits test (immediate memory). Those over 8 years had the speed of information processing test and 